\title{
PENDIDIKAN KESIAPSIAGAAN BENCANA TANAH LONGSOR UNTUK SISWA ANAK USIA DINI DENGAN METODE DONGENG BERBASIS MEDIA POP UP BOOK DI PAUD DEWI SARTIKA KECAMATAN BERGAS
}

\author{
Andi Irwan Benardi* \\ *Pendidikan Geografi Fakultas Ilmu Sosial Universitas Negeri Semarang
}

\begin{tabular}{l}
\hline \hline INFO ARTIKEL \\
\hline Riwayat Artikel: \\
Diterima: $19-4-2018$ \\
Disetujui: $28-5-2018$
\end{tabular}

\section{Kata kunci:}

Preparedness Education; Landslide; Pop Up Book; Media

\begin{abstract}
ABSTRAK
Abstract: This study aims to design and compose a fairy tale script about landslide disaster preparedness, design and make pop up book about landslide disaster preparedness, and to know effectiveness of storytelling method with Pop Up Book media in education of landslide disaster preparedness. The research method used is experimental method. Sampling is done by purposive sampling technique in low class, while data collection in this research through observation, interview and questionnaire. The analysis technique used is descriptive analysis and $\mathrm{N}$-Gain analysis. The results show the design and the composition of fairy tale script suitable for children of early childhood Dewi Sartika District Bergas. The design and making of the pop up book is adjusted to the text of the fairy tale and considering the elements of motion and the three dimensional elements, and the effectiveness of the application of storytelling method with the media Pop up book in education for landslide disaster preparedness for PAUD students Dewi Sartika Kecamatan Bergas included in the effective category with the gain of 0.528 or in the moderate effectiveness category.
\end{abstract}

\begin{abstract}
Abstrak: Penelitian ini bertujuan untuk mendesain dan menyusun naskah dongeng tentang kesiapsiagaan bencana tanah longsor, mendesain dan membuat pop up book tentang kesiapsiagaan bencana tanah longsor, dan mengetahui tingkat efektivitas metode mendongeng dengan media Pop Up book dalam pendidikan kesiapsiagan bencana tanah longsor. Metode penelitian yang digunakan adalah metode eksperimen. Pengambilan sampel dilakukan dengan teknik purposive sampling pada kelas rendah, sedangkan pengumpulan data dalam penelitian ini melalui observasi, wawancara dan kuesioner. Teknik analisis yang digunakan adalah analisis deskriptif dan analisis N-Gain. Hasil penelitian menunjukkan desain dan susunan naskah dongeng sesuai untuk anak usia PAUD Dewi Sartika Kecamatan Bergas. Desain dan pembuatan pop up book disesuaikan dengan naskah dongeng dan mempertimbangkan unsur gerak serta unsur tiga dimensi, dan tingkat efektivitas penerapan metode mendongeng dengan media Pop up book dalam pendidikan kesiapsiagaan bencana tanah longsor untuk siswa PAUD Dewi Sartika Kecamatan Bergas termasuk dalam kategori efektif dengan nilai gain sebesar 0,528 atau dalam kategori efektivitas sedang.
\end{abstract}


Jurnal Pendidikan Geografi:

Kajian, Teori, dan Praktik dalam Bidang Pendidikan dan Ilmu Geografi

Tahun 23, Nomor 2, Jun 2018, Hal 85-93

\author{
Alamat Korespondensi: \\ Andi Irwan Benardi \\ Pendidikan Geografi Fakultas Ilmu Sosial \\ Universitas Negeri Semarang \\ Sekaran Gunungpati Semarang \\ E-mail: andi@mail.unnes.ac.id
}

\title{
PENDAHULUAN
}

Kecamatan Bergas merupakan salah satu kecamatan yang perlu mendapat sorotan dalam hal kajian tanah longsor, karena disamping beberapa daerahnya memiliki persentase kelerengan yang termasuk dalam kategori terjal, kepadatan penduduk di daerah tersebut pun tinggi. Berdasarkan peta resiko bencana tanah longsor Kabupaten Semarang tahun 2015, salah satu kelurahan salah satu kelurahan yang memiliki tingkat resiko tinggi adalah Kecamatan Bergas. Berdasarkan hal tersebut, maka perlu diadakannya suatu pendidikan kesiapsiagaan bencana tanah longsor.

Pendidikan kesiapsiagaan bencana tanah longsor yang akan dilakukan oleh peneliti merupakan upaya pendidikan bagi siswa usia PAUD. Hal tersebut didasarkan pada pernyataan camat Bergas yang menyebutkan bahwa di Kecamatan Bergas belum pernah diadakan suatu pendidikan kesiapsiagaan bencana tanah longsor untuk usia siswa PAUD.

Tujuan dari penelitian ini adalah untuk (1) mendesain dan menyusun naskah dongeng tentang kesiapsiagaan bencana tanah longsor, (2) mendesain dan membuat Pop up book tentang kesiapsiagaan bencana tanah longsor, (3) mengetahui tingkat efektivitas metode mendongeng berbantuan Pop up book dalam pendidikan kesiapsiagaan bencana longsor untuk siswa PAUD Dewi Sartika Di Kecamatan Bergas.

\section{METODE}

Metode mendongeng peneliti pilih karena mempertimbangkan subjek penelitian yang berada pada rentang umur 4-5 tahun. Kebermaknaan cerita terletak pada aktivitas menyimak cerita itu sendiri, terutama karena kegiatan berbahasa yang paling banyak dilakukan anak adalah menyimak. Kajian Paul Ramkin mengenai kegiatan berkomunikasi anak menunjukkan bahwa 45\% waktu anak digunakan untuk menyimak. Barulah setelah itu anak menghabiskan 30\% waktunya untuk berbicara, 16\% untuk membaca, dan $9 \%$ untuk menulis (Cox dalam Mustofa, 2015). Hal ini berarti bahwa menyimak berfungsi sentral dalam kehidupan anak sekaligus merupakan aktivitas dasar manusia yang membuatnya memiliki banyak pengetahuan.

\section{Hasil Penelitian}

\section{HASIL DAN PEMBAHASAN}

\section{Gambaran Umum Objek Penelitian}

Penelitian ini dilakukan di PAUD Dewi Sartika. PAUD Dewi Sartika berada di Jl.Sumbing No. 316A, Semarang dan merupakan satu-satunya PAUD yang berada di Kecamatan Bergas. Jumlah siswa di PAUD Dewi Sartika adalah 242 siswa dengan rasio jumlah laki-laki dan perempuan adalah 128 dan 114. Data lebih lengkap dapat dilihat pada Tabel 1. 
Jurnal Pendidikan Geografi:

Kajian, Teori, dan Praktik dalam Bidang Pendidikan dan Ilmu Geografi

Tahun 23, Nomor 2, Jun 2018 , Hal 85-93

Tabel 1. Jumlah Siswa dan Jumlah Rombel di PAUD Dewi Sartika

\begin{tabular}{ccc}
\hline Kelas & Jumlah Siswa & Jumlah Rombel \\
\hline $\mathbf{1}$ & 40 & 2 \\
$\mathbf{2}$ & 41 & 2 \\
$\mathbf{3}$ & 44 & 2 \\
Total & 125 & \\
\hline \multicolumn{3}{c}{ Sumber: Kemendikbud, 2017 }
\end{tabular}

Berdasarkan tabel 1, peneliti memilih kelas 2 sebagai kelas penelitian. Kelas 2 dengan jumlah 41 siswa dibagi menjadi dua rombel. Rombel A digunakan sebagai kelas eksperimen dan rombel B digunakan sebagai kelas uji coba.

\section{Desain dan Penyusunan Naskah Dongeng}

Penyusunan naskah dongeng dilakukan melalaui tahapan berikut:

1) Menentukan Tema

Naskah dongeng ini bertema tentang kesiapsiagaan bencana tanah longsor yang dikemas secara sederhana dan bersifat istana sentris.

2) Menentukan Pusat Pengisahan

Pusat pengisahan atau sudut pandang menggambarkan posisi pengarang dalam dongeng yang dibuat. Sudut pandang yang pengarang pilih adalah sebagai author-omniscient (pengarang serba tahu) atau pengarang berperan sebagai orang ketiga. Hal tersebut pengarang pilih atas dasar kesederhanaan agar dongeng yang telah dibuat dapat dengan mudah dipahami oleh siswa PAUD kelas 2.

3) Menentukan Perwatakan

Penentuan watak tokoh dilakukan dengan metode analitik, yaitu pengarang secara langsung memaparkan watak tokoh dengan jalan menyebutkan sifat-sifatnya. Penggambaran watak tokoh secara langsung dapat mempermudah siswa dalam memahami isi cerita dongeng.

4) Menentukan Latar

Penentuan latar dilakukan sesuai dengan tema yang diambil. Tempat yang menjadi latar pada penelitian ini adalah di istana dan lereng bukit.

5) Menentukan Alur cerita

Alur cerita yang dipilih oleh pengarang adalah alur maju. Alur tersebut memiliki tahapan penyituasian, tahap pemunculan konflik, tahap peningkatan konflik, tahap klimaks, dan tahap penyelesaian.

Setelah tahapan tersebut terpenuhi, maka disusunlah kerangka naskah dongeng menjadi naskah dongeng yang utuh dengan judul "Awas.. Ada Longsor!!"

\section{Desain dan Penyusunan Desain Pop Up Book}

Desain dan pembuatan media Pop Up Book dilakukan melalui tahapan sebagai berikut:

1) Menyiapkan Alat dan Bahan

Peralatan yang digunakan dalam pembuatan Pop Up adalah laptop dengan aplikasi Adobe Photoshop CS4, gunting, cutter, penggaris, stapler, alat tulis, double tape, dan seperanglat alat pewarna.

Bahan yang digunakan dalam pembuatan Pop Up Book ini adalah kertas manila, kertas karton, kertas ivory, kertas HVS, kertas CTS, lem, dan glitter.

2) Penyusunan Lembar Pop Up Berdasarkan Naskah Dongeng 
Jurnal Pendidikan Geografi:

Kajian, Teori, dan Praktik dalam Bidang Pendidikan dan Ilmu Geografi

Tahun 23, Nomor 2, Jun 2018, Hal 85-93



Gambar 1. Sketsa Karakter Pangeran Anggara

Lembar 1 : Berisi tahapan alur penyituasian

Lembar 2-3: Berisi tahapan alur pemunculan konflik

Lembar 4-6: Berisi tahapan alur peningkatan konflik

Lembar 7-8: Berisi tahapan alur klimaks

Lembar 9 : Berisi tahapan alur penyelesaian

3) Membuat Desain Karakter

Pembuatan desain karakter dilakukan dengan bantuan aplikasi Adobe Photoshop CS4. Cara pembuatannya dimulai dengan membuat sketsa karakter kemudian melakukan pewarnaan pada sketsa tersebut dengan menggunakan aplikasi Adobe Photoshop CS4. Proses tersebut dapat dilihat pada gambar 1 dan 2.



Gambar 2. Sketsa Karakter Raja

4) Merakit Pop Up tiap Lembar

Proses perakitan tiap lembar pop up dilakukan setelah menyelesaikan semua desain karakter dan latar. Perakitan dilakukan dalam lembar-lembar yang terpisah.

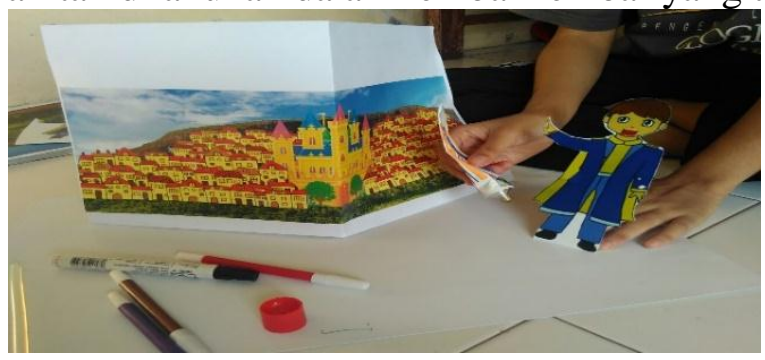

Gambar 3. Proses Perakitan Tiap Lembar Pop Up

5) Menyusun Lembar Pop Up menjadi sebuah Pop up book

Setelah semua Pop Up dalam tiap lembar tersusun, lembaran-lembaran Pop Up tersebut disusun menjadi sebuah Pop up book. Penyusunan tersebut dilakukan dengan mengguankan double tape dan stapler. 
Jurnal Pendidikan Geografi:

Kajian, Teori, dan Praktik dalam Bidang Pendidikan dan Ilmu Geografi

Tahun 23, Nomor 2, Jun 2018 , Hal 85-93

\section{Tingkat Efektivitas Metode Mendongeng dengan Media Pop Up Book}

Pengambilan data untuk mengukur tingkat efektivitas metode mendongeng dengan media Pop up book dilakukan melalui pengukuran hasil belajar siswa, aktivitas siswa saat pembelajaran, dan respon siswa terhadap pembelajaran yang dilakukan. Pelaksanaan kegiatan pendidikan kesiapsiagaan bencana tanah longsor dengan metode mendongeng dilaksanakan selama 2 pertemuan.

\section{Hasil Belajar Siswa}

Berdasarkan nilai pretest dan posttest, dapat diketahui adanya peningkatan jumlah siswa yang berhasil melampaui nilai KKM. Jumlah siswa yang melampaui nilai KKM pada saat pretest yaitu sebanyak 4 siswa atau sebesar 20\%. Sedangkan jumlah siswa yang melampaui nilai KKM pada saat post test yaitu sebanyak 16 siswa atau sebesar $80 \%$. Peningkatan yang terjadi adalah sebesar $60 \%$. Peningkatan hasil belajar terjadi karena adanya stimulus berupa dongeng dan media pop up book. Gambaran mengenai peningkatan tersebut dapat dilihat pada gambar 4.

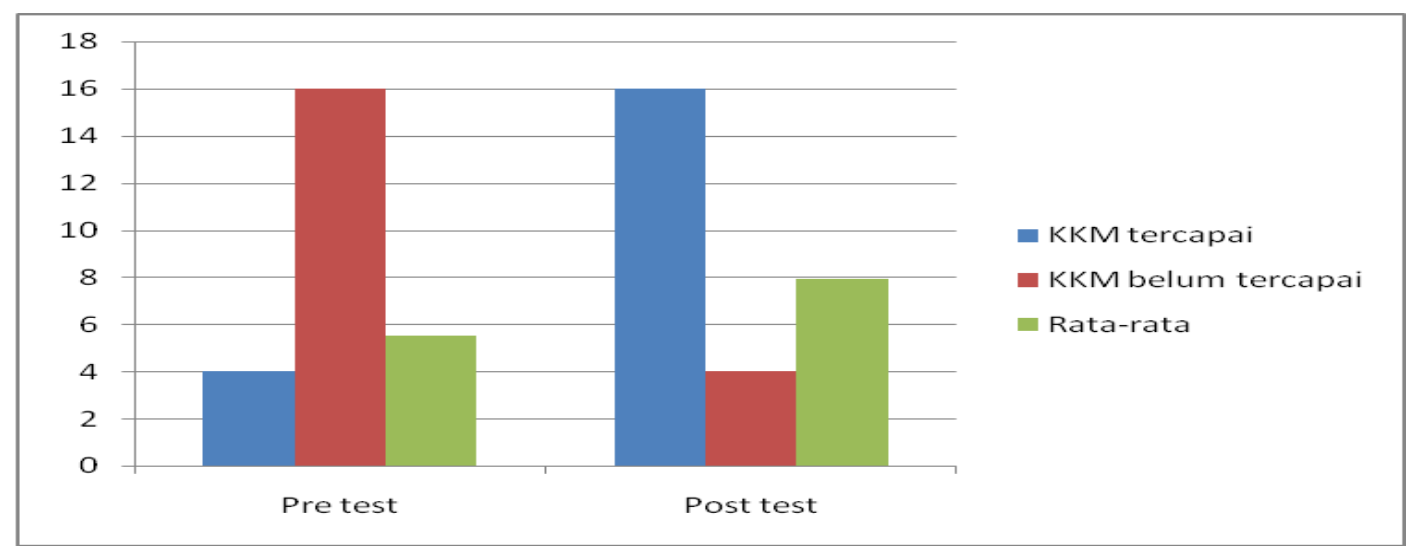

Gambar 4. Perbandingan Hasil Pre Test dan Post Test

\section{Aktivitas Siswa Saat Pembelajaran}

Hasil penelitian mengenai aktivitas siswa saat pembelajaran menunjukkan bahwa dari 20 siswa terdapat 4 siswa yang berada pada kategori sangat tinggi, 12 siswa berada pada kategori tinggi, dan 4 siswa pada kategori rendah. Hasil persentase dapat dilihat pada gambar 5 .



Gambar 5. Persentase Data Aktivitas Belajar Siswa

Selain dirinci per siswa, hasil penelitian mengenai aktivitas belajar siswa juga dirinci berdasarakan indikator pengamatanya. Rincian hasil penelitian aktivitas belajar siswa dapat dilihat pada tabel 2 . 
Jurnal Pendidikan Geografi:

Kajian, Teori, dan Praktik dalam Bidang Pendidikan dan Ilmu Geografi

Tahun 23, Nomor 2, Jun 2018, Hal 85-93

Tabel 2. Analisis Data Aktivitas Belajar Siswa Dirinci per Indikator

\begin{tabular}{lll}
\hline \multicolumn{1}{c}{ Indikator } & Skor & \multicolumn{1}{c}{ Kategori } \\
\hline Oral Activities & 60 & Tinggi \\
Visual Activities & 61 & Tinggi \\
Mental Activities & 60 & Tinggi \\
Listening Activities & 66 & Sangat Tinggi \\
Emotional Activities & 56 & Rendah \\
Writing Activities & 59 & Rendah \\
\hline
\end{tabular}

Sumber : Data Primer, 2017

Berdasarkan rincian pada tabel 2, dapat diketahui bahwa indikator oral, visual, dan mental activities berada pada kategori tinggi serta indikator listening activities berada pada kategori sangat tinggi. Hal tersebut disebabkan karena penyampaian materi melalui dongeng dan pop up book, membuat siswa lebih tertarik untuk memberikan feedback positif berupa, memperhatikan, teratur, dan aktif berinteraksi dengan guru dan siswa dalam membahasan materi. Berbeda dengan empat indikator sebelumnya, indikator emotional dan writing activities berada pada kategori rendah. Hal tersebut dikarenakan ada beberapa siswa yang terlalu antusias terhadap media yang didemonstrasikan. Selain itu, anak lebih tertarik untuk fokus menyimak dari pada di sertai dengan aktivitas menulis.

\section{Respon Siswa}

Berdasarkan hasil respon siswa yang diperolah saat pretest dan posttest, terlihat adanya peningkatan respon siswa dalam pembelajaran. Peningkatan tersebut terjadi pada ketiga indikator dengan persentase peningkatan sebesar 17,75\% atau dengan peningkatan 14 frekuensi pada indikator rasa senang siswa terhadap pembelajaran, peningkatan sebesar $7 \%$ atau dengan peningkatan 6 frekuensi pada indikator antusiasme siswa dan peningkatan sebesar 5\% atau dengan peningkatan 3 frekuensi pada indikator motivasi belajar siswa. Peningkatan respon siswa terjadi karena siswa tertarik dengan metode mendongeng dan media pop up book yang digunakan dalam proses pembelajaran. Peningkatan tersebut dapat dilihat pada gambar 6 .

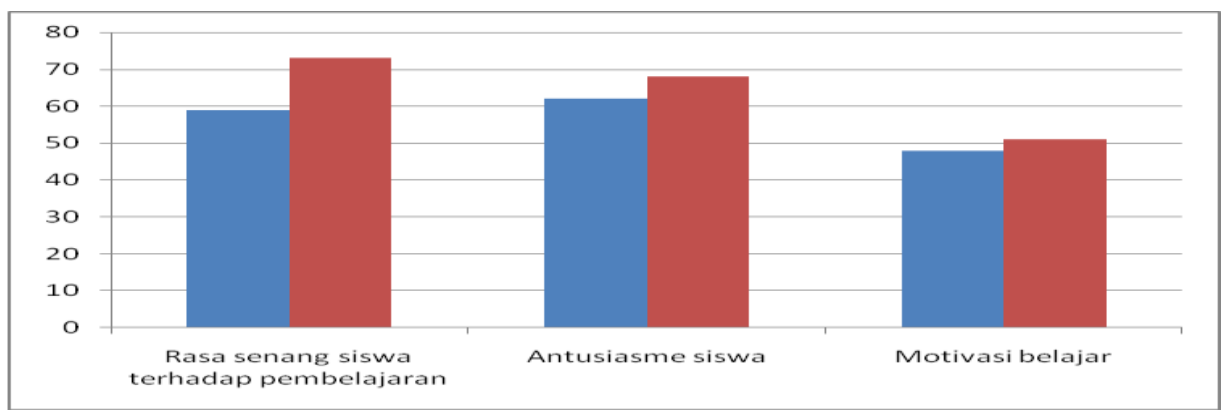

Tingkat Efektivitas Pembelajaran

Gambar 6. Peningkatan Respon Siswa

Pengukuran tingkat efektivitas metode mendongeng dengan media pop up book dalam pendidikan kesiapsiagaan bencana tanah longsor dilakukan dengan menggunakan perhitungan gain ternormalisasi (Meltzer, 2002). Perhitungan tersebut menghasilkan data NGain sebesar 0.53 yang berarti memiliki tingkat efektivitas sedang. 
Jurnal Pendidikan Geografi:

Kajian, Teori, dan Praktik dalam Bidang Pendidikan dan Ilmu Geografi

Tahun 23, Nomor 2, Jun 2018 , Hal 85-93

\section{PEMBAHASAN}

Berdasarkan Peta Rawan Longsor Kabupaten Semarang Tahun 2015, KelurahaDewi Sartika merupakan daerah yang rawan terhadap bencana tanah longsor. Kenampakan fisik Kelurahan Dewi Sartika merupakan daerah berlereng dan padat oleh pemukiman penduduk. Hal tersebut membuat beban yang ditopang oleh tanah miring tersebut melebihi kapasitas sehingga rawan terhadap bencana tanah longsor. Rawannya Kelurahan Dewi Sartika terhadap bencana tanah longsor memaksa masyarakat dan perangkat KelurahaDewi Sartika untuk siap siaga menghadapi bencana tanah longsor yang secara tiba-tiba dapat terjadi.

Bencana tanah longsor dapat terjadi kapan pun dan menimpa siapapun, sehingga pendidikan kesiapsiagaannya pun hendaknya tidak hanya diberikan kepada masyarakat usia dewasa saja, melainkan kepada masyarakat usia sekolah dalam hal ini adalah anak-anak usia PAUD.

Pendidikan kesiapsiagaan bencana tanah longsor untuk usia anak-anak belum pernah diadakan di KelurahaDewi Sartika, sehingga membuat anak-anak usia kelas rendah di KelurahaDewi Sartika kurang memiliki pengetahuan mengenai bencana tanah longsor. Hal tersebut dibuktikan melalui hasil pre test yang menunjukkan jumlah siswa yang melampaui nilai KKM pada saat pre test yaitu sebanyak 4 siswa atau sebesar $20 \%$.

Pendidikan kesiapsiagaan bencana tanah longsor yang diberikan kepada siswa usia kelas rendah di PAUDDewi Sartika menggunakan metode mendongeng dengan bantuan media Pop Up Story Book. Metode mendongeng dengan media Pop up book dipilih karena hal tersebut merupakan suatu media komunikasi yang ampuh dalam mentransfer ide dan gagasan kepada anak dalam sebuah kemasan yang menarik. Selain itu, dapat pula membuat anak lebih peka dan dapat mengasah daya ingat siswa (Mustofa, 2015:92).

Menurut Mustofa (2015:77), dongeng yang sesuai untuk anak adalah dongeng substansi yang sederhana. Penyusunan naskah dongeng dalam penelitian ini dilakukan sesederhana mungkin, namun tetap mengedepankan kualitas cerita agar informasi mengenai kesiapsiagaan bencana tanah longsor dapat tersampaikan dan dapat dengan mudah dipahami oleh siswa. Penyusunan naskah dongeng secara sederhana dilakukan agar tidak terjadi kesalahpahaman dalam memaknai isi dongeng.

Dongeng yang bertemakan kesiapsiagaan bencana tanah longsor tersebut bersifat istana sentris dengan judul "Awas.. Ada Longsor!!“. Cerita dongeng tersebut beralur maju dengan tahapan alur berupa tahap penyituasian, tahap pemunculan konflik, tahap peningkatan konflik, tahap klimaks, dan tahap penyelesaian. Tahapan alur tersebut dapat dilihat pada lampiran 23.

Dongeng "Awas.. Ada Longsor!!" berasosiasi dengan media pop up book. Sejalan dengan pendapat dari Dzuanda dalam Pramesti (2015:3), pembuatan pop up book sebagai media penunjang dalam penyampaian dongeng bertema kesiapsiagaan bencana tanah longsor tersebut mempertimbangkan unsur tiga dimensi dan unsur gerak. Bahan yang digunakan dalam pembuatan pop up book ini adalah lem, kertas ivory, kertas HVS, alat tulis, seperangkat alat pewarna, kertas karton dan plastik mika. Proses pembuatan melalui beberapa tahap yaitu, penyiapan alat dan bahan, penyusunan lembar pop up berdasarkan naskah dongeng, pembuatan desain karakter, perakitan pop up tiap lembar, dan penyusunan lembar pop up menjadi sebuah pop up book.

Menurut Sinambela (2008:78), pelaksanaan pembelajaran dikatakan efektif apabila tiga dari empat kriteria berikut terpenuhi, yaitu: (1) kemampuan guru dalam mengelola pembelajaran baik, (2) aktivitas siswa tinggi, (3) hasil belajar siswa melampaui KKM atau tuntas, dan (4) respon siswa terhadap pembelajaran positif. Hasil belajar siswa menunjukkan jumlah siswa yang melampaui nilai KKM pada saat post test yaitu sebanyak 16 siswa atau 
sebesar $80 \%$, atau dengan peningkatan sebesar $60 \%$. Peningkatan hasil belajar tersebut dikarenakan adanya peningkatan daya pemahaman siswa terhadap materi yang disampaikan, dalam hal ini adalah materi kesiapsiagaan bencana tanah longsor melalui metode dongeng dan media pop up book. Selain pengamatan yang dilakukan berdasarkan hasil belajar, efektivitas dari metode mendongeng berbantuan media Pop up book ini dilihat melalui tingkat aktivitas siswa saat pemberian materi. Hasil analisis menunjukkan, dari 6 indikator aktivitas siswa terdapat 3 indikator (oral activities, visual activities, dan mental activities) yang berada pada kategori tinggi, 1 indikator (listening activities) yang berada pada kategori sangat tinggi, dan 2 indikator (emotional activities dan writing activities) yang berada pada kategori rendah. Indikator oral, visual, dan mental activities berada pada kategori tinggi serta indikator listening activities berada pada kategori sangat tinggi disebabkan karena penyampaian materi melalui dongeng dan pop up book membuat siswa lebih tertarik untuk memberikan feedback positif berupa, memperhatikan, teratur, dan aktif berinteraksi dengan guru dan siswa dalam membahasan materi. Berbeda dengan empat indikator sebelumnya, indikator emotional dan writing activities berada pada kategori rendah. Hal tersebut dikarenakan ada beberapa siswa yang terlalu antusias terhadap media yang didemonstrasikan. Selain itu, anak lebih tertarik untuk fokus menyimak dari pada di sertai dengan aktivitas menulis.

Menurut DePorter dalam Hidayah (2015), respon yang baik menandakan bahwa pembelajaran yang dilakukan mampu meningkatkan hasil belajar siswa dan menyenangkan. Hal ini dapat dilihat dari rasa senang siswa terhadap pembelajaran, antusiasme yang tinggi, dan motivasi belajar siswa meningkat. Respon siswa pada saat pendidikan kesiapsiagaan bencana tanah longsor mengalami peningkatan. Peningkatan tersebut terlihat melalui hasil data respon siswa pada saat pendidikan kesiapsiagaan bencana tanah longsor tanpa perlakukan dan saat diberikannya pendidikan kesiapsiagaan bencana tanah longsor dengan metode mendongeng berbantuan media Pop up book. Peningkatan tersebut terjadi pada ketiga indikator dengan persentase peningkatan sebesar $17,75 \%$ atau dengan peningkatan 14 frekuensi pada indikator rasa senang siswa terhadap pembelajaran, peningkatan sebesar 7\% atau dengan peningkatan 6 frekuensi pada indikator antusiasme siswa dan peningkatan sebesar 5\% atau dengan peningkatan 3 frekuensi pada indikator motivasi belajar siswa. Peningkatan tersebut diakibatkan adanya stimulus berupa dongeng dan media Pop Up Book yang membuat siswa lebih tertarik untuk belajar.

\section{KESIMPULAN}

Berdasarkan hasil penelitian dan uraian pembahasan, dapat disimpulkan bahwa desain naskah dongeng sesuai untuk anak usia PAUD kelas rendah, desain pop up book berasosiasi dengan naskah dongeng dan memiliki unsur gerak serta unsur tiga dimensi. Metode mendongeng dengan bantuan media Pop up book efektif untuk digunakan dalam pendidikan kesiapsiagaan bencana tanah longsor. Hal tersebut dapat dilihat dari adanya peningkatan jumlah siswa yang melampaui KKM sebelum diberi perlakuan dan setelah diberi perlakuan. Selain itu, rata-rata aktivitas siswa selama mengikuti pendidikan kesiapsiagaan bencana tanah longsor dengan metode mendongeng berbantuan media Рор up book adalah tinggi dan adanya peningkatan pada semua indikator respon siswa terhadap pembelajaran semakin memperkuat bahwa metode mendongeng dengan bantuan media Pop up book efektif digunakan dalam pendidikan kesiapsiagaan bencana tanah longsor. Tingkat efektivitas dari metode ini termasuk dalam kategori efektivitas sedang. 


\section{DAFTAR RUJUKAN}

Akhmad Erfin F, Apik Budi S, dan Juhadi. 2017. Pelaksanaan Program Siaga Bencana di Sekolah Menengah Pertama pada Kawasan Rawan Bencana. Dalam Edu Geography. No 3. Hal 86-95.

Badan Pusat Statistik. 2010. Jumlah dan Distribusi Penduduk. http://sp2010.bps.go.id/.

Badan Pusat Statistik. 2014. Kecamatan Bergas dalam Angka 2013. Semarang: BPS Jateng. Desmita. 2013. Psikologi Perkembangan. Bandung: Remaja RoPAUDakarya.

Hidayah Eka N, Tukidi, Apik Budi S. 2015. 'Efektivitas Model Pembelajaran Simulasi Berbantuan Permainan Geo Explore pada Mata Pelajaran Geografi Siswa Kelas XI IPS SMA Negeri 2 Semarang'. Dalam Edu Geography. No. 4. Hal 51.

Kurniawan, L., dkk. 2014. IRBI: indeks Risiko Bencana Indonesia. Sentul: Direktorat Pengurangan Risiko Bencana Deputi Bidang Pencegahan dan Kesiapsiagaan.

Meltzer, D. E. 2002. 'The Relationship between Mathematics Preparation and Learning Gains in Physic: A Possible "Hidden Variable" Pretest Scores'. Dalam AM. J. Phys. No 70. Hal 1259-1268.

Mustofa, Bisri. 2015. Melejitkan Kecerdasan Anak melalui Dongeng. Yogyakarta: Parama Ilmu.

Sinambela, Pardomuan N.J.M. 2008. 'Faktor-faktor Penentu Keefektivan Pembelajaran dalam Model Pembelajaran Berdasarkan Masalah (Problem Based Instruction')'. Dalam Generasi Kampus. No 2. hal 74-85.

Sugiyono, 2015. Statistika untuk Penelitian. Bandung: Alfabeta. 